\title{
Duties of psychiatrists: treat the patient or protect the public?
}

\author{
Gwen Adshead
}

In this paper I will be discussing the professional duties of psychiatrists. I will argue that there is an ethical tension at the heart of psychiatric practice between the psychiatrist's professional duties to his or her patient, and what professional duties there might be to protect public safety. It may be of some comfort to clinicians to know that this tension has exercised the best minds for centuries, including thinkers such as Marcus Aurelius nearly 800 years ago (Spruit, 1998).

\section{Duties of doctors}

The primary professional identity of psychiatrists is medical, and it may be useful to review the extent of doctors' legal and professional duties. Doctors' general duties are not extensive or peculiar to medicine. Doctors are legally required to be registered to practise in the UK, under the Medical Act 1983 (Kennedy \& Grubb, 1994), in order to hold themselves out as medical practitioners. Doctors are expected to respect criminal law statutes in the same way as other citizens. Civil law requires doctors to carry out their professional duties of care with reasonable care and skill, in accordance with a body of reasonable medical opinion (Bolam $v$. Friern Hospital Management Committee, 1957), so long as this has a logical basis (Bolitho v. City and Hackney Health Authority, 1997). If they do so, they will not be found to be negligent. The professional duty of care includes gaining consent from patients and giving them appropriate information before interventions. If asked questions by patients, doctors must answer truthfully (Sidaway v. Board of Governors of the Bethlem Royal Hospital, 1985).

In addition to any general legal duties, the General Medical Council (1995) outlines 14 specific professional duties in its own guidance, entitled "Duties of a doctor".

The main point here is that the duties of doctors are generally seen as being owed to a particular patient or patients, and not to the community at large. Although there are some branches of medicine where third party interests are considered part of the doctor's duty of care (see below), the emphasis is on duties to individual patients.

\section{Duties of psychiatrists}

The duties of psychiatrists do not differ in kind from those of other doctors. However, the execution of

Box 1. Duties of doctors ( in general terms)

To register with the General Medical Council

To follow General Medical Council and other professional guidance

To carry out their duty of care with reasonable professional skill

To obtain consent and provide information about significant risks of harm

To tell the truth if asked

To respect the criminal law

Gwen Adshead is Consultant and Senior Honorary Lecturer in Forensic Psychotherapy at Broadmoor Hospital (Crowthorne, Berkshire RG45 7EG) and St George's Hospital Medical School. She is also a consultant psychiatrist at the Traumatic Stress Clinic, Middlesex Hospital. She trained in forensic psychiatry at St George's Hospital and holds a Masters degree in Medical Law and Ethics from King's College London. She is currently researching the attachment characteristics of child abusers, and moral reasoning in people with antisocial personality disorder. She has particular interest in the psychological and psychodynamic aspects of competence to consent or refuse treatment and has published a number of papers on ethical dilemmas in psychiatry. 
those duties is affected by the effects of mental illness on patients. Thus, questions about consent, for example, are raised far more frequently in psychiatric practice than questions about information.

In the following section, I will address the question of the duties of National Health Service (NHS) psychiatrists to individual patients in more detail. Interestingly, the nature and scope of the duties of psychiatrists have been examined in legal rather than psychiatric settings, so much of the ensuing discussion will be of a legal nature. In general, the cases and statutes referred to will be English law - where relevant, I will make reference to other UK legislations.

\section{Psychiatrist-patient relationship: consent}

The basic duty of care requires a psychiatrist to treat patients who need their care, to the best of their ability. What, however, is the nature of a psychiatrist's duty to those who need help but either cannot consent, or are refusing it? The Mental Health Acts of the UK (including England, Wales, Scotland and Northern Ireland) all provide measures whereby patients can receive treatment for mental conditions without their consent. These measures are generally similar in their structure and content, although there are some significant differences (mainly in relation to personality disorder and its definition; Gunn \& Taylor, 1993).

Currently, individuals do not have to be deemed incompetent (i.e lacking in capacity to make decisions for themselves) before the mental health legislation is invoked. This gatekeeping decision is a clinical one, that is, whether or not the patient is suffering from 'mental disorder' as defined under the various Acts. Note too, that this is not a diagnostic process, since the categories of mental disorder cited have no relationship to diagnoses listed in either DSM-IV or ICD-10, and there is no requirement for such a diagnosis (Department of Health and Home Office, 1990). It is, therefore, perfectly possible under English law for a mentally competent adult without a psychiatric diagnosis to be detained under the Mental Health Act. The same is true in Scotland and Northern Ireland.

The English and Scottish Mental Health Act gives approved professionals (whether doctors in England and Wales, or sheriffs in Scotland) power to detain citizens who are mentally ill or otherwise mentally vulnerable. However, it has not been clear whether the legislation imposes a duty to detain. The English House of Lords' judgement in the case of $R . v$ Bournewood Community and Mental Health NHS Trust (1998) examined the treatment of patients admitted to hospital who are incompetent to give consent. The House of Lords stated that doctors have not only a statutory duty of care to such patients to act in their best medical interests, but also a duty based on the legal principle of necessity (at p. 297(j)). Arguably, it may be the duty of the psychiatrist to detain an incompetent patient, if he or she deems it to be medically necessary.

Interestingly, the Northern Ireland Mental Health Order does make indirect reference to a duty to detain. The criteria for both emergency and non-emergency compulsory admission are met if failure to detain would create a risk of harm to the patient or others. This risk is strictly defined, making the decision to detain more complex.

\section{Assessment of capacity to consent}

As Lord Steyn noted in Bournewood, the assessment of competence is a complex business, and is affected by many factors, of which the patient's mental health status is only one. There is no evidence that mental illness makes a patient incompetent, ipso facto - rather, the presence of certain types of symptom clusters, such as some types of delusion or excessively high or low mood, may be relevant. Further, the outcome of any assessment of competence may be affected by contributions from the environment, prescribed medication and by the assessor. Reliability in assessment may be improved by training; even so, research into the assessment of competence suggests that it requires a fairly lengthy interview, certainly with the patient, but possibly also with interested family members (Grisso \& Appelbaum, 1998).

The Bournewood judgement makes no mention of the vexed issue of patients who refuse treatment, and the assessment of whether, or to what extent, a refusal of psychiatric treatment can ever be judged a competent decision. Their Lordships seem to assume that all refusals are incompetent ones. Ultimately, the decision in Bournewood leaves the assessment of competence to consent to or refuse treatment to the judgement of the psychiatrist.

Box 2. Psychiatrists' duty of care to admitted patients who lack capacity

(after Bournewood)

If a patient is incompetent to give consent, the psychiatrist has a duty to act in the patient's best medical interests 
Detention and treatment is then justified on the grounds of (clinical) necessity.

In the future, psychiatrists may have to demonstrate that they assessed capacity in detained patients, and provide some grounds for a finding of incompetence. Psychiatrists may, therefore, need some additional professional education in this area. At present, a basic test of competence is provided in the case of $C$ (1994; see Box 3).

A competent patient can still be detained under the Mental Health Act and treated without consent in the usual way (Fennell, 1996). It remains to be seen whether there is a duty of psychiatrists to detain patients who are mentally disordered and who may pose a risk to themselves or others, but yet retain competence to consent and refuse treatment on the 'C' test (Box 3).

\section{Third party interests}

I have argued that psychiatrists have professional duties specific to psychiatry, such as a duty of care to patients who lack capacity to make decisions for themselves. I turn now to consider the psychiatrist's duties to third parties, that is, to other people who may have an interest in the patient's health.

It may be helpful to consider the general duties of doctors with regard to third parties. There are several branches of medicine where parties other than the patient are involved in patient care. Public health is the most obvious, where in fact there is no individual 'patient' at all. Obstetrics and paediatrics are both clinical domains where there may be more people involved in the doctor-patient relationship. Occupational health physicians have dual loyalties - the duty to the employer may outweigh any duty to the patient. Finally, most general practitioners appreciate that their patients' difficulties are influenced by social, work and family networks, and good medical care entails liaison with those networks.

Box 3. Test of competence to consent (after $C$, 1994)

Can the patient take in the information presented to them?

Can they believe it?

Can they make a choice?

NB This test does not apply to consent to research procedures
In a similar way, psychiatrists who are working with chronically ill patients appreciate the importance of contact with the involved carers and relatives. Any psychiatrist working with patients who have long-term dependency needs (such as in the fields of child psychiatry, old age or learning disability) is likely to have experience of working with networks of patient carers. In these settings, the interests of relatives and carers have to be considered, while not allowing them to 'trump' those of the patient.

Whether the professional duty of care extends to include carer networks is another matter. For example, is there a duty to apprise them of any or every change in medication, especially if the patient seems well able to manage this aspect of treatment without help? Recent homicide inquiries have emphasised the importance of communication with relatives - but this rather begs the question of who will decide what information is passed on to whom. Many mentally ill patients still wish to claim some privacy and some degree of respect for confidentiality - even patients with histories of violence (W. v. Egdell, 1990).

In terms of legal duty, there is no definitive statement in case law about the duties of psychiatrists to relatives. However, it is likely to be a matter of good practice to involve carers in the care of patients, and respond sensitively and reflectively to the relationship between patients and their carers. One might envisage a sliding scale of involvement, in which the closer to and more involved the carer/ relative is with the care of the patient on a day-today basis, the greater their claim to information and involvement. This is probably commonplace in a clinical setting - but there may come a time when it is more formalised, perhaps along the lines of the Patient's Charter (Department of Health, 1997).

\section{Psychiatrists' duties with regard to risk}

This section deals with the question of the psychiatrist's duties in relation to risk, especially risk posed to others by patients with a mental illness. There is a long history in medicine of doctors managing risk posed by different types of illness. The key feature of the doctor's involvement is a postulated causal relationship between the illness and the risk. The normal scope of the duty of care does not extend to require the doctor to intervene in any situation where the patient poses a risk to others - only in those situations where there is a risk as a result of an illness. (An exception to this argument may be made in relation to child protection, as 
discussed below.) Any doctor may consider that he or she has a duty as a concerned citizen to intervene - but this is not a professional duty.

In general medicine, the most common examples of this type of professional duty relate to the management of infectious diseases, including sexually transmitted diseases. Some diseases are notifiable under public health legislation, and the English Public Health Act 1984 allows for the involuntary examination and detention in hospital of people suspected of having a notifiable disease. Similarly, accidents must be reported to the police under the Road Traffic Act, and doctors may be required to give information about patients to bodies responsible for maintaining public safety. The message here is that individual claims to privacy and liberty may be overridden in the interests of public health and safety - and this is true for all patients and doctors. This is essentially a political and ethical argument in which the claims of the community are privileged over individuals' claims (Brazier \& Harris, 1996).

Public health concerns tend to impact most on the confidentiality aspect of the duty of care. The most common situation now in general practice usually relates to child protection, and all doctors are expected to disclose relevant information if they have good reason to think that a child is at risk of harm (Department of Health et al, 1991). The doctor's duty of care to a vulnerable child includes notification of a possible source of harm to that child, with the aim of preventing future harm. The public interest in identifying and preventing child abuse justifies the breach of confidentiality required. What is interesting about the child protection issue is that it is usually the victim, rather than the perpetrator, who is being identified - and further, that the risk is not so much to do with any type of illness, but a type of illegal behaviour, namely physical violence.

In contrast, psychiatrists may be concerned that a patient under their care is a possible perpetrator of harm - harm which is seen as a function of the perpetrator's mental illness. The ethical and legal duties of psychiatrists faced with a potentially risky patient are not clearly established. The relevant mental health legislation may be used in such a case. In English law, if a risky patient obviously lacks capacity to make decisions for him- or herself, then (after Bournewood) there may be a duty to act in his or her best medical interests - which could theoretically include detention under the Act.

However, if the patient is not lacking in capacity (and this could include some patients with personality disorder), then it is not clear that any of the mental health acts or orders mandates the clinician to detain - they only give the power to do so, if the statutory criteria are fulfilled. One can offer treatment to the patient, and hopefully he or she will take up the offer. But if an individual refuses treatment, and the psychiatrist does not feel legal detention is warranted, then questions arise about the management of any risk posed by that individual.

\section{A duty to protect? Mr Poddar and $\mathrm{Mr}$ Clunis}

In 1994, mandatory inquiries after homicides and suicides by people with mental illnesses were introduced (Department of Health, 1994). Many inquiries have taken place since then, often at considerable expense and with the enormous benefit of hindsight. At least one inquiry has stated that the psychiatrist's duty of care includes training in the proper use of the Care Programme Approach (Crawford et al, 1997). Most inquiries have also recommended training in and familiarity with risk assessment and management (Petch \& Bradley, 1997). However, the question remains whether the psychiatric duty of care includes preventing patients from causing any possible risk to themselves or others - and, when the chips are down, whether the psychiatrist is always expected to put the concerns of third parties before those of the patient.

The most quoted law case on this issue is one from the USA. Most psychiatrists will be familiar with the case of Tatiana Tarasoff, who was killed by a Mr Poddar. Poddar had previously told his therapist of his homicidal thoughts towards Miss Tarasoff. The therapist informed local police, who questioned Poddar, who denied any threat to Miss Tarasoff. Two months later (quite a long time!), he shot Miss Tarasoff. Although the case is often discussed in relation to the ethics of breaches of confidentiality, the real issue of interest for mental health professionals is the Californian Supreme Court's ruling about the professional duties of therapists. They concluded that therapists, in a Tarasoff-like situation, have a duty to warn and to protect potential victims (Tarasoff $v$. Regents of the University of California et al, 1976). By extension, the therapist's (or treating psychiatrist's) duty of care to Mr Poddar was 'trumped' by the claims of the potential victim - or perhaps better understood as being 'on hold'.

The English courts have not yet had to deal with a Tarasoff-like case, although it cannot be far off. The two most relevant cases to date are W. $v$. Egdell (1990) and Clunis v. Camden \& Islington Health Authority (1998). In the case of Egdell, the Court of Appeal concluded that it was legitimate for a psychiatrist to breach confidentiality in the public interest, and that there might be a duty to so where the psychiatrist perceives a risk of violence to others. 
This is an indication that there are circumstances when the court would expect a psychiatrist to privilege obligations to third parties over obligations due to the patient.

In the well-known case of Clunis, $\mathrm{Mr}$ Clunis sought damages from a health authority, claiming that as a result of their negligence he had suffered harm namely that he had killed a man, been found guilty of manslaughter on the grounds of diminished responsibility, and subsequently detained. The Court of Appeal concluded that public policy prevented him from benefiting from his illegal actpartly because he bore some responsibility for the offence. However, the Clunis judgement does suggest indirectly that if Mr Clunis had been so mentally ill that he either did not know what he was doing or did not know it was wrong (i.e. the McNaughten test of legal 'insanity'), then he might have a claim in negligence against the health authority. If upheld, this would imply that (in England and Wales) a health authority's duty of care (and by extension, that of its psychiatric staff) includes preventing people like Mr Clunis from harming other people.

The Clunis judgement is consistent with the traditional view in moral philosophy and jurisprudence that competent adults are responsible for their own actions. The issue, therefore, is that of the definition of competence. The Clunis judgement suggests that psychiatrists might have a duty to protect the public from their patients, if the patient is sufficiently mentally ill - so ill that they lack competence to be responsible for criminal acts. Essentially, the question relates to the degree of control a person might have over him- or herself, and whether it would be reasonable to expect someone else to be in control of him or her. The Court of Appeal in Clunis are suggesting that unless violent individuals are 'McNaughten mad', then they bear some responsibility for their actions, even if they have a mental disorder - and, therefore, that no other person (like their psychiatrist) can be responsible (see Box 4).

At present, therefore, psychiatrists and health authorities are not responsible for the illegal actions

Box 4. Responsibility of psychiatrists for their patients' actions

Psychiatrists may have a duty to prevent their patients from acting criminally if the patient is so ill that they either (a) do not know what they are doing, or (b) do not know that it is wrong (the McNaughten rules) of their patients. However, the Clunis judgement is likely to be challenged again - and psychiatrists may need to become better acquainted with the McNaughten rules.

\section{A duty to warn? Foreseeability and risk assessment}

There remains the question raised by Tarasoff as to whether a psychiatrist's duty of care includes a duty to warn (Box 5). In some American states, the duty to warn has been held to apply only where there is an identifiable person at risk - that is, 'Mrs Brown of 43 Acacia Avenue', rather than 'all red-headed women in Manchester'. In this country, the decision in Egdell, the Working Together guidelines (Department of Health et al, 1991) and current General Medical Council guidance (General Medical Council, 1995) all indicate a prima facie duty to breach confidentiality and warn an identifiable victim where there is a possible risk from a patient.

Arguably, the more information one has about potential risk to a victim, the stronger the claim that he or she has to be warned - this argument would be consistent with the law on negligence and foreseeability (Kennedy \& Grubb, 1994, p. 671) and a recent court judgement (Palmer. $v$. Tees Health Authority and Another, 1998). There is no particular reason why this should apply only to psychiatrists - many general practitioners are likely to be in similar situations, especially in relation to family violence. The many recommendations of homicide inquiries usually include the improvement of communication among mental health care professionals (Peay, 1996; Petch \& Bradley, 1997) - presupposing some duty of psychiatrists to communicate their concerns about potentially risky patients, which justifies any breach of confidentiality.

\section{Psychiatrists' duty to protect the public}

What might the nature and scope of a duty to protect look like? And how does it relate to the duty of care to individual patients? In several USA jurisdictions, psychiatrists may fulfil their duty of care by implementing local mental health legislation. The UK equivalent would be to detain a potentially risky person under the relevant legislation, on the grounds that the individual was mentally disordered and that detention was necessary for the protection of others. However, risk to others is only one criterion for assessment and detention, and is 
Box 5. The duty to warn

Psychiatrists do not have an absolute duty of confidentiality

General Medical Council guidance - breach of confidentiality may be justified if there is an identified person at risk

Working Together (Department of Health et $a l, 1991)$ - it is good practice for doctors to report where a child is thought to be at risk.

Egdell - there may be a duty to breach confidentiality in the public interest

Palmer - there may be a duty to protect an identifiable individual

not sufficient alone. Although many psychiatric patients who pose a risk to others would fulfil both criteria, some would not.

The primary aim of UK mental health legislation is the protection of the health and well-being of people with mental illnesses. The point about the Tarasoff decision is that it states explicitly that the protection of the public, and the prevention of harm to the public, are primary duties of any mental health care professional. If courts were to go down this road, then this would be highly significant for psychiatry. Psychiatrists will be familiar with previous complaints that they are just policemen in another guise. If a primary duty of psychiatrists were to protect the public, then they would indeed resemble policemen. However, policemen have a public mandate to protect the public, and funding and training to do this. Legal powers are given to the police, which include the infringement of civil liberties under certain conditions, in the public interest. Of course, UK mental health legislation also provides the power to infringe civil liberties - but primarily in the interests of the individual patient, not society. It is not a mandate for tidying away dangerous people.

It may be that the psychiatric professional duty of care is developing into a primary duty to protect the public from potentially dangerous patients. If this is the case, then it needs to be explicitly stated perhaps written into consultant contracts. Better training in public protection, similar to that of the police, would be needed. There might also be a case for indemnity against prosecution, such as is held by the police, who currently cannot be held liable for failure to prevent a crime.

Interestingly, psychiatry is not the only medical speciality which may be involved in the prevention of violence. In Ontario, all doctors are now mandated to report a risk of violence to the relevant authorities (Ferris, 1998).
It has been argued that doctors have a duty to prevent violence, and that there should be greater cooperation between doctors and the police including the automatic reporting of all victims of violence to the police (Shepherd et al, 1995; Shepherd \& Lisles, 1998). Covert video and closed-circuit television have been used in hospitals to detect and prevent crime where it occurs on hospital premises (Southall \& Samuels, 1995). A national health service is part of the community, and the community's interests will also be those of the NHS. Given the costs to the NHS of physical violence, whether or not caused by mental disorder, there may be a case for seeing the prevention of violence as a medical matter, in which psychiatrists could and should play their part.

In counter-argument, there are many causes of community violence, and mental illness is arguably one of the least important. There is a role for psychiatry in the management of violence caused by the small proportion of perpetrators who are mentally ill - but this cannot be a basis for an argument that violence prevention generally is a medical concern. The control of community violence is a political issue, and doctors have no professional expertise in political matters. There is a danger that psychiatrists will act politically, not clinically, in a way that may be unjust to individuals and harmful to the profession. Finally, if psychiatrists make public protection their primary duty, then their other duties of care to the patient are likely to suffer owing to what has been called "irreconcilable role conflict" (Strasburger et al, 1997). The mentally ill are already disenfranchised by illness, poverty and stigma they need more help and protection from psychiatry, not less.

\section{Developing the law: European jurisdictions, and the Scoping Study Committee}

It may be helpful to look at how European mental health law approachs the duties of psychiatrists (brief summaries of different European mental health laws may be found in Koch et al (1996)). What strikes the reader is the emphasis on the protection of the individual patient's rights, and the duty of the psychiatrist to the individual. For example, no mental health law seems to impose a duty to detain the mentally ill - but all describe the power to detain if (and only if) certain criteria are fulfilled. These are familiar and relate to either the health and welfare of the patient, or risk to others. There are differences in how risk to others is considered - for example, 
Italian law justifies detention when there is a "severe" risk to others; French law specifies "immediate" danger to others. Under French law, coercive procedures are controlled by administrative or judicial authorities - reflecting perhaps more transparently the public interest in detention. Dutch law is one of the few legislations which makes the link between risk and mental illness explicit - involuntary detention is only justified on the grounds of "dangerousness" where it is the "result" of mental illness and there is no other way to deal with the danger.

These laws reflect a previous reaction against psychiatry, once perceived as coercive and restrictive of civil liberties. However, what English psychiatrists have seen more recently is a swing of the pendulum the other way - that is, a push to develop mental health law with an emphasis on the protection of the public, and the development of the psychiatrist's role in this protection. Thus, draft proposals for reform of the English Mental Health Act include a "right to assessment" which in turn gives rise to a "duty to assess" (Scoping Study Committee, 1999). They also include a proposal by which "compulsory" (rather than "involuntary") treatment may be imposed on competent patients, where there is a "substantial risk of serious harm... to others". This is still not a mandate but does suggest that the Scoping Committee understands the management of risk as being a significant part of psychiatry's professional role - even when the risk is posed by people whose mental health problems do not affect their capacity to look after themselves.

\section{Conclusion}

Psychiatrists need guidance about their duties to patients and the public. The General Medical Council's guidance is insufficiently specific. Unlike its American and Australian counterparts, the Royal College of Psychiatrists has no code of ethics which might address the tension between duties to patients' health and welfare, and any duties to public safety. Thus, at present, psychiatrists must fall back on the law. In England at least, the Scoping Committee's proposals for revising the 1983 Act are likely to stimulate new debate about an old problem.

\section{References}

Brazier, M. \& Harris, J. (1996) Public health and private lives. Medical Law Review, 4, 171-192.
Crawford, C., DeVaux, M., Ferris, R., et al (1997) The Report into the Care and Treatment of Martin Mursell. London: Camden \& Islington Health Authority.

Department of Health (1994) Guidance on the Discharge of Mentally Disordered People, and their Continuing Care in the Community. NHS Executive HSG (94)27 \& LASS (94)4. London: NHS Executive.

- (1997) Mental Health Services: The Patient's Charter. Leeds: Department of Health.

- \& Home Office (1990) Code of Practice, Mental Health Act 1983. London: HMSO.

- - \& Department of Education (1991) Working Together: Under the Children Act 1989. London: HMSO.

Fennell, P. (1996) Treatment Without Consent. London: Routledge.

Ferris, J. (1998) Ontario doctors mandated to report violence. British Medical Journal, 316, 1033-1034.

General Medical Council (1995) Guidance to doctors. London: GMC.

Gunn, J. \& Taylor, P. (1993) Forensic Psychiatry: Clinical, Legal and Ethical Issues, pp. 21-118. London: Butterworth Heinemann.

Grisso, T. \& Appelbaum, P. (1998) Assessing Competence to Consent to Treatment. Oxford: Oxford University Press.

Kennedy, I. \& Grubb, A. (1994) Medical Law: Text and Materials. London: Butterworth.

Koch, H., Reiter-Theil, S. \& Helchen, H. (eds) (1996) Informed Consent in Psychiatry. Baden Baden: Nomos VerlagsGesellschaft.

Peay, J. (ed.) (1996) Inquiries after Homicide. London: Duckworth.

Petch, E. \& Bradley, C. (1997) Learning the lessons from homicide inquiries: adding insult to injury? Journal of Forensic Psychiatry, 8, 161-184.

Scoping Study Committee (1999) Draft Outline Proposals: Review of the Mental Health Act 1983. London: Department of Health.

Shepherd, J., Morley, R., Adshead, G., et al (1995) Should doctors be more proactive towards victims of violence? British Medical Journal, 311, 1617-1619.

— \& Lisles, C. (1998) Towards multiagency violence prevention and victim support. British Journal of Criminology, 38, 351-370.

Southall, D. \& Samuels, M. (1995) Some ethical issues surrounding covert video surveillance - a response. Journal of Medical Ethics, 21, 104-105, 115.

Spruit, J. (1998) The penal conceptions of the Emperor Marcus Aurelius in respect of lunatics: reflections on D.I.. 18,14. International Journal of Law and Psychiatry, 21, 315334.

Strasburger, L., Gutheil, T. \& Brodsky, A. (1997) On wearing two hats: role conflict in serving as both psychotherapist and expert witness. American Journal of Psychiatry, 154, 448-456.

\section{Legal cases}

Bolam v. Friern Hospital Management Committee (1957) 1 WLR 582.

Bolitho v. City and Hackney Health Authority (1997) House of Lords 4 All ER 771.

$C$ (Refusal of medical treatment) Re: (1994) FLR 31.

Clunis v. Camden and Islington Health Authority (1998) 2. WLR 902.

R. v. Bournewood Community and Mental Health NHS Trust, ex parte L. House of Lords (1998) 3 All ER 289.

Palmer v. Tees Health Authority and Another (1998) Court of Appeal, Times Law Report, 1 June 1998.

Sidaway 0 . Board of Governors of the Bethlem Royal Hospital (1985) AC 871

Tarasoff $v$. Regents of the University of California et al $131 \mathrm{Cal}$ Rpt 14, 551 P2d34 (Cal 1976).

W. v. Egdell (1990) 1 All ER 835. 


\section{Multiple choice questions}

1. The legal duties of psychiatrists include:

a respect for the criminal law

b registration with the General Medical Council

c duty to assess patients referred

d having Section 12/20 approval

e a duty to detain patients under mental health legislation if criteria are met.

2. Criteria for mental competence/capacity to make treatment decisions (English law only):

a the patient can take in information presented

b the patient makes judgement consistent with his or her normal choices

c the patient makes judgement consistent with medical advice

$d$ the patient believes the information presented

e the patient shows evidence of being able to make a choice.
3. Under English law, if a patient presents a risk to others, the psychiatrist:

a must breach confidentiality in order to advise police

b may be justified in breaching confidentiality in the public interest

c may be required as a matter of good practice to breach confidentiality if a child is at risk

d may be justified in breaching confidentiality by warning a named potential victim

e has a legal duty to warn others.

\section{MCQ answers}

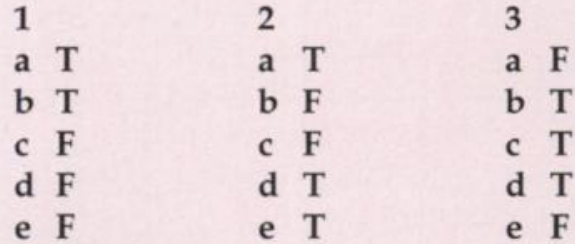

1

e $\mathbf{T}$

\section{Royal College of Psychiatrists}

\section{TRAINING DAY IN ELECTROCONVULSIVE THERAPY}

\section{King's Fund, Cavendish Square, London}

Tuesday 9 November 1999

The Royal College of Psychiatrists' Special Committee on Electroconvulsive Therapy is to offer another ECT Training Day at the King's Fund, London. The format will be a combination of presentations and participatory workshops. The Training Day will include sessions of particular interest to nurses and anaesthetists, as well as psychiatrists involved in ECT practice.

A programme and booking form can be obtained from:

Mrs A. Fewings, Conference Office, Royal College of Psychiatrists,

17 Belgrave Square, London SW1X 8PG

Telephone +44 (0)171 2352351 ext. 142, Fax +44 (0)171 2596507

E-mail: afewings@rcpsych.ac.uk 